\title{
Safety, tolerability, and efficacy of fixed combination therapy with dorzolamide hydrochloride $2 \%$ and timolol maleate $0.5 \%$ in glaucoma and ocular hypertension
}

\author{
This article was published in the following Dove Press journal: \\ Clinical Ophthalmology \\ 19 November 2010 \\ Number of times this article has been viewed
}

\author{
Nicholas P Bell \\ José L Ramos \\ Robert M Feldman \\ Robert Cizik Eye Clinic, Department \\ of Ophthalmology and Visual Science, \\ The University of Texas Medical \\ School at Houston, Houston, \\ Texas 77030, USA
}

\begin{abstract}
Glaucoma is a collection of diseases characterized by multifactorial progressive changes leading to visual field loss and optic neuropathy most frequently due to elevated intraocular pressure (IOP). The goal of treatment is the lowering of the IOP to prevent additional optic nerve damage. Treatment usually begins with topical pharmacological agents as monotherapy, progresses to combination therapy with agents from up to 4 different classes of IOP-lowering medications, and then proceeds to laser or incisional surgical modalities for refractory cases. The fixed combination therapy with the carbonic anhydrase inhibitor dorzolamide hydrochloride $2 \%$ and the beta blocker timolol maleate $0.5 \%$ is now available in a generic formulation for the treatment of patients who have not responded sufficiently to monotherapy with beta adrenergic blockers. In pre- and postmarketing clinical studies, the fixed combination dorzolamide-timolol has been shown to be safe and efficacious, and well tolerated by patients. The fixed combination dorzolamide-timolol is convenient for patients, reduces their dosing regimen with the goal of increasing their compliance, reduces the effects of "washout" when instilling multiple drops, and reduces the preservative burden by reducing the number of drops administered per day.

Keywords: dorzolamide, timolol, glaucoma, ocular hypertension, elevated IOP, fixed combination therapy
\end{abstract}

\section{Introduction to glaucoma, ocular hypertension management, and patient compliance \\ Background}

Glaucoma is the leading cause of irreversible blindness throughout the world, accounting for blindness in 5.1 million persons according to the World Health Organization 1995 statistics. In the United States (US), glaucoma is the second leading cause of blindness and most frequent cause of blindness among blacks. ${ }^{1}$ The term glaucoma refers to a collection of diseases with diverse clinical and histopathologic manifestations characterized by progressive, distinctive changes in the visual field and the optic nerve. ${ }^{1,2}$

Aqueous humor is produced by the ciliary body and drains out of the eye primarily through the trabecular meshwork within the anterior chamber angle. In open angle glaucoma $(\mathrm{OAG})$, elevation in IOP results from an increased resistance to aqueous outflow at the level of the trabecular meshwork. ${ }^{2}$ Elevated intraocular pressure (IOP), or ocular hypertension $(\mathrm{OH})$, is an important risk factor for the development of glaucoma, although some patients may develop characteristic optic nerve and visual field changes despite normal IOP. ${ }^{1-3}$ 


\section{Epidemiology}

The prevalence of OAG in persons 40 years and older is estimated to be around $1 \%$ to $5 \%$ of the population in the US, ${ }^{3} 1 \%$ to $3 \%$ in Europe, ${ }^{4,5} 1 \%$ to $>8 \%$ in Africa, ${ }^{4,5} 1 \%$ to $4 \%$ in Asia, ${ }^{4,5}$ and $2 \%$ to $3 \%$ in Australia. ${ }^{4,5}$ The incidence of "definite" OAG is about $0.1 \%$ to $0.2 \%$ per year in mainly European populations, and an even higher incidence of $0.5 \%$ per year has been reported for black participants in one study, which rises to $1.0 \%$ per year if "probable" cases of OAG are included. ${ }^{3}$

\section{Medical treatment of glaucoma}

Lowering the IOP is recognized to retard or prevent additional damage to the optic nerve. Treatment for glaucoma is generally administered with topical eye drops. The goal of therapy is to lower the IOP below the threshold at which damage to the optic nerve is incited. In addition to being efficacious, the treatment must be safe and well tolerated by the individual patient. To minimize the risk of local and systemic side effects, clinicians typically employ the fewest medications necessary to achieve the desired therapeutic effect.

Since the 1970s, topical beta blocker medications such as timolol maleate $0.5 \%$ (Timoptic ${ }^{\circledR}$; Merck \& Co., Inc., Whitehouse Station, NJ, USA) dosed once or twice daily have been utilized as first-line therapy choices in the treatment of glaucoma. ${ }^{6}$ Prior to that, cholinergic agonists (topical pilocarpine, carbachol, and phospholine iodide), nonspecific adrenergic agonists (topical epinephrine [Epifrin ${ }^{\circledR}$; Allergan, Inc., Irvine, CA, USA] and dipivefrin hydrochloride[Propine ${ }^{\circledR}$; Allergan, Inc.]), and oral carbonic anhydrase inhibitors (acetazolamide [Diamox ${ }^{\circledR}$; Lederle, Pearl River, NY, USA] and methazolamide [Neptazane ${ }^{\circledR}$; Lederle, Pearl River, NY, USA]) were the mainstays of glaucoma therapy; however, some of these (eg, epinephrine and dipivefrin) are no longer routinely used due to their side effect profiles. ${ }^{6}$ Over the past 20 years, the armamentarium of topical medications to treat glaucoma expanded to include selective $\alpha_{2}$-adrenergic agonists (apraclonidine $0.5 \%$ [Iopidine ${ }^{\circledR}$; Alcon Laboratories, Inc., Fort Worth, TX, USA] and brimonidine tartrate (in concentrations from $0.1 \%$ to $0.2 \%$ ) [Alphagan ${ }^{\circledR} /$ Alphagan $\mathrm{P}^{\circledR}$; Allergan, Inc.]), topical carbonic anhydrase inhibitors (dorzolamide hydrochloride 2\% [Trusopt ${ }^{\circledR}$; Merck \& Co., Inc.] and brinzolamide 1\% [Azopt ${ }^{\mathbb{}}$; Alcon Laboratories, Inc.]), and prostaglandin $\mathrm{F}_{2 \alpha}$ analogs (latanoprost $0.005 \%$ [Xalatan ${ }^{\circledR}$, Pfizer, Inc. New York, NY, USA], travoprost $0.004 \%$ [Trava$\tan ^{\circledR} /$ Travatan $Z^{\circledR} ;$ Alcon Laboratories, Inc.], and bimatoprost $0.03 \%$ [Lumigan ${ }^{\circledR}$; Allergan, Inc.]).
Patients with OAG are usually treated initially with monotherapy with 1 drug class (eg, timolol maleate $0.5 \%$ ) and other classes of medications are added as necessary to lower the IOP into the desired target range. Many of the patients who are using IOP-lowering treatments require more than 1 class of medication to reduce their IOP to the desired levels. In the treatment arm of the Ocular Hypertension Treatment Study, medications were added until the goal of IOP $<24 \mathrm{mmHg}$ and at least $20 \%$ reduction in IOP from baseline was maintained. At 5 years, 2 or more topical medications were required for $39.7 \%$ of the patients and 3 or more medications were prescribed for $9.3 \%$ of the patients in the medication treatment arm of the study. ${ }^{7}$ In a large observational study where 1990 patients with primary OAG (POAG) or $\mathrm{OH}$ were enrolled in 9 countries, less than half $(48 \%)$ of the patients remained on beta blocker monotherapy after 2 years, $56 \%$ of the patients who required additional therapies being switched to a topical fixed combination treatment. ${ }^{8}$

\section{Patient compliance}

Patient compliance includes adherence (how well the patient follows the physician's prescribed orders) and persistence (how long the patient remains on therapy). Patient noncompliance with medications is a concern regardless of the medication that is prescribed. Patients' adherence to the prescribed daily regimen decreases with increased dosing frequency. ${ }^{9}$ Reviews of studies that analyze compliance have shown that less complex dosing regimens resulted in better adherence to the plan. Claxton et al reviewed a total of 76 studies where compliance was measured with electronic monitoring devices rather than less accurate methods such as patient self-report, blood-level monitoring, prescription refills, or pill count data. Mean dose-taking compliance across these 76 studies was $79 \%$ for once-daily dosing, $69 \%$ for twice-daily dosing, $65 \%$ for 3 -times-daily dosing, and $51 \%$ for 4 -times-daily dosing. ${ }^{10}$ Noncompliance with recommended medical therapy is a major problem in the treatment of a chronic and typically asymptomatic disease such as glaucoma because the treatment lacks positive feedback (such as symptomatic relief) and may cause local ocular and/or systemic side effects. ${ }^{11}$ A historical literature review by Greenberg related the frequency of dosing and other influences with patient compliance in medication taking. Once-a-day and twice-a-day regimens were associated with significantly better compliance $(73 \% \pm 6 \%$ [range $42 \%$ to $93 \%$ ] and $70 \% \pm 5 \%$ [range $50 \%$ to $94 \%$ ], respectively) than were 3-times-daily ( $52 \% \pm 7 \%$ [range $18 \%$ to $89 \%$ ]) and 4 -times-daily ( $42 \% \pm 5 \%$ [range $11 \%$ to $66 \%$ ]) dosing regimens. ${ }^{12}$ 


\section{Combination therapy}

Fixed combination formulations may improve compliance by reducing the number of daily eye drops, thereby simplifying the dosing regimen. ${ }^{11,13-15}$ Pilocarpine and epinephrine were combined to treat glaucoma as early as the 1960s. After timolol maleate $0.5 \%$ became available in 1978 , fixed combinations of timolol-pilocarpine and timolol-epinephrine followed. Dorzolamide hydrochloride $2 \%$ was approved by the US Food and Drug Administration (FDA) in 1995 for 3 -times-daily dosing. Dorzolamide hydrochloride $2 \%$ and timolol maleate $0.5 \%$ were formulated as a fixed combination product (Cosopt ${ }^{\circledR}$; Merck and Co., Inc.) and approved by the FDA in 1998 to provide a more convenient dosing regimen for patients requiring multiple medications. ${ }^{9}$ The IOP-lowering effect of the fixed combination dorzolamide-timolol was greater than that of either of its components administered as monotherapy. This combination is generally well tolerated and provides a convenient alternative to concomitant therapy with its individual components. ${ }^{9}$ Another inherent benefit of fixed combination therapy versus concomitant therapy with multiple drugs is that fixed combination therapies decrease the preservative load to which the patients' eyes are exposed. They also eliminate the effects of having the first instilled drug being diluted or "washed out" by the second instilled eye drop. The dorzolamide-timolol fixed combination was released to market as a generic in October 2008. ${ }^{16}$

A fixed combination of timolol maleate $0.5 \%$ and brimonidine tartrate $0.2 \%$ (Combigan ${ }^{\circledR}$; Allergan, Inc.) has also been available in the US since 2007. Fixed combinations of timolol maleate $0.5 \%$ with latanoprost $0.005 \%$ (Xalacom $^{\circledR}$; Pfizer, Inc.), travoprost $0.004 \%$ (Extravan ${ }^{\circledR}$ or Duotrav ${ }^{\circledR}$; Alcon Laboratories, Inc.), bimatoprost $0.03 \%$ (Ganfort $^{\circledR}$; Allergan, Inc.), and brinzolamide 1\% (Azarga ${ }^{\circledR}$; Alcon Laboratories, Inc.) are available outside the US. A fixed triple combination of timolol maleate $0.5 \%$, dorzolamide hydrochloride $2 \%$, and brimonidine tartrate $0.2 \%$ (Krytanek Ofteno $^{\circledR}$; Laboratorios Sophia, Mexico) has recently become available as well. ${ }^{17}$

\section{Pharmacology Pharmacodynamics}

Although both dorzolamide hydrochloride $2 \%$ and timolol maleate $0.5 \%$ decrease elevated IOP by decreasing aqueous humor production, they each appear to have a different mechanism of action at the molecular level and they appear to have an additive or synergistic effect when administered together either concomitantly or as part of a fixed combination product. ${ }^{18}$ Carbonic anhydrase inhibitors decrease aqueous secretion due to lack of bicarbonate ions. ${ }^{19}$ Dorzolamide is a carbonic anhydrase inhibitor that is highly selective for the carbonic anhydrase isoenzyme II (CA-II) and lowers IOP by inhibiting CA-II in the ocular ciliary process, thus decreasing aqueous humor production while also improving hemodynamic ocular blood flow. Dorzolamide also has the systemic effect of inhibiting the CA-II isoenzyme in erythrocytes. ${ }^{18}$ When administered topically in the eye, beta blockers reduce IOP by a mechanism that involves reduced production of aqueous humor by the ciliary body, which is physiologically activated by cAMP. ${ }^{19}$ Timolol is a nonselective beta-adrenoreceptor antagonist (beta- 1 and beta-2), with no local anesthetic, membrane stabilizing, or sympathomimetic properties, which lowers IOP by inhibiting aqueous humor production with no hemodynamic effects on ocular blood flow. Timolol has the systemic effect of reducing heart rate and blood pressure. While the maximal daily dose that is usually applied locally to the eye is small relative to the usual daily doses used for systemic administration of beta blockers to treat conditions such as hypertension, enough of the timolol may be absorbed from the eye as to cause serious adverse effects on the heart and airways of susceptible individuals. ${ }^{18,19}$

\section{Pharmacokinetics}

No specific information on the pharmacokinetic properties of the fixed combination of dorzolamide-timolol has been published, and thus the pharmacokinetics of the individual components are discussed herein. After topical ocular administration, dorzolamide enters the systemic circulation via drainage through the nasolacrimal duct and absorption from the nasopharyngeal mucosa. Systemically absorbed dorzolamide binds mainly to CA-II in the red blood cells with plasma protein binding of the drug at $33 \%$. Dorzolamide is metabolized slowly by the cytochrome $\mathrm{P} 450$ (CYP) 2B1/2, CYP2E1, and CYP3A2 isoenzymes in the liver to a single $\mathrm{N}$-desethyldorzolamide metabolite, which also accumulates in erythrocytes where it binds primarily to carbonic anhydrase isoenzyme I (CA-I). Dorzolamide and $\mathrm{N}$-desethyldorzolamide are excreted predominantly via the renal route, accordingly use of the fixed combination is not recommended (in the US) or is contraindicated (in Europe) in patients with severe renal impairment.

Timolol is absorbed systemically in the same way as is dorzolamide. Instillation of 2 drops of timolol maleate $0.5 \%$ into the eyes of 20 patients undergoing cataract surgery produced timolol concentrations ranging from $150 \mathrm{ng} / 100 \mathrm{mg}$ of aspirated aqueous humor in the first 1 to 
2 hours to $10 \mathrm{ng} / 100 \mathrm{mg}$ aspirated aqueous humor towards the end of 7 hours. Between $5 \%$ and $46 \%$ of the calculated absorbed dose of timolol maleate $0.5 \%$ was excreted renally over 24 hours following ocular administration of the drug as 2 drops in each eye. ${ }^{18}$

\section{Available formulations of fixed combination dorzolamide-timolol}

In addition to the brand name dorzolamide-timolol fixed combination product $\left(\mathrm{Cosopt}^{\circledR}\right)$, as the time of writing, at least 4 pharmaceutical manufacturers are currently producing generic versions of the fixed combination dorzolamide-timolol. ${ }^{20}$ A review of the key characteristics of the available formulations of fixed combination dorzolamide-timolol as documented in the respective products' package inserts (labeling), including the concentration of the 2 active ingredients, the choice of preservative used and the concentration thereof in the formulation, as well as a review of the inactive ingredients, revealed that there are no significant differences in these parameters among the available formulations. Anecdotally, patients have reported differences in side effects among the various generic products, but no controlled trials have been published that document these observations.

\section{Preservative-free fixed combination of dorzolamide-timolol}

Preservative-free Cosopt $t^{\circledR}$ has been developed as an alternative for those patients allergic or sensitive to the commonly used preservative benzalkonium chloride (BAK). One study has shown that this formulation lowers IOP by $38 \%$ from baseline at 8 weeks without significantly increasing ocular discomfort (as measured by the Glaucoma Symptom Scale [GSS-SYMP-6]). ${ }^{21}$ A second report demonstrated that both the preservative-free and preservative-containing formulations of dorzolamide-timolol fixed combination were equivalent in efficacy in IOP changes at peak and trough. Additionally, this study reported similar tolerability between the 2 preparations. ${ }^{22}$

\section{Fixed combination of brinzolamide-timolol}

A fixed combination of timolol plus a different topical carbonic anhydrase inhibitor (Azarga ${ }^{\circledR}$, brinzolamide 1\% plus timolol $0.5 \%$ ) has recently been marketed worldwide except for the US. Initial studies have demonstrated equivalent safety and efficacy compared with the fixed combination of dorzolamide and timolol. ${ }^{23}$ Reports of improved comfort and tolerability with the brinzolamide-timolol fixed combination have been published ${ }^{24-26}$ but the some of the marketing claims have been disputed. ${ }^{27}$

\section{Efficacy studies}

The ocular hypotensive efficacy of dorzolamide-timolol fixed combination therapy has been compared to various single ocular hypotensive medications including monotherapy with either of its components (dorzolamide hydrochloride $2 \%$ or timolol maleate $0.5 \%),{ }^{9,28}$ bimatoprost $0.03 \%,{ }^{29,30}$ latanoprost $0.005 \%,{ }^{31-34}$ or travoprost $0.004 \% .^{31,34,35}$ Comparisons have also been made between fixed combination therapy with dorzolamide-timolol and various concomitant dual therapy options including concomitant therapy with its components (dorzolamide hydrochloride 2\% plus timolol maleate $0.5 \%),{ }^{11,36,37}$ brimonidine tartrate $0.2 \%$ plus timolol maleate $0.5 \%,{ }^{38,39}$ or brimonidine tartrate $0.2 \%$ plus latanoprost $0.005 \% .{ }^{40}$ Additionally, the dorzolamidetimolol fixed combination therapy has been compared to other available fixed combination therapies including latanoprost-timolol, ${ }^{41-43}$ and brimonidine-timolol. ${ }^{44,45}$ The fixed combination dorzolamide-timolol therapy has also been studied retrospectively in patients who were being treated with dorzolamide-timolol but had previously not responded to prostaglandin analogs. ${ }^{46}$ Prophylactic treatment after phacoemulsification surgery was studied comparing dorzolamide-timolol fixed combination therapy with brimonidine tartrate $0.2 \%$ monotherapy and a control group of patients not receiving any ocular hypotensive medications. ${ }^{47}$ Some fixed combination therapies of prostaglandins (latanoprost or travoprost) with timolol maleate $0.5 \%$ are available outside the US but did not achieve FDA approval for use in the US because they did not meet the specific additional demonstrated efficacy targets above and beyond what can be accomplished with a prostaglandin. ${ }^{6}$

\section{Comparisons with monotherapy of its components dorzolamide hydrochloride $2 \%$ or timolol maleate $0.5 \%$}

The IOP-lowering effect of the dorzolamide-timolol fixed combination has been found to be greater than that of either of its components when they are each administered as monotherapy., ${ }^{9,2}$ In a 3-month, parallel, randomized, multicenter clinical trial comparing dorzolamide-timolol fixed combination therapy dosed twice daily with monotherapy with either dorzolamide hydrochloride $2 \% 3$ times daily or timolol maleate $0.5 \%$ twice daily in patients who had washed out all ocular hypotensive medications, IOP 
was measured at morning trough (hour 0 ) and peak (2 hours post-dose). IOP reduction was found to be greater in the fixed combination therapy group than in the dorzolamide or timolol groups. At morning trough (hour 0 ) of the 3-month visit, the mean IOP reduction from baseline was $27.4 \%(-7.7 \mathrm{mmHg})$ for the fixed combination therapy, $15.5 \%(-4.6 \mathrm{mmHg})$ for the dorzolamide group, and $22.2 \%(-6.4 \mathrm{mmHg})$ for the timolol group. At morning peak measurement (hour 2) of the 3-month visit, the mean IOP reduction from baseline was $32.7 \%$ (-9.0 $\mathrm{mmHg}), 19.8 \%(-5.4 \mathrm{mmHg})$, and $22.6 \%$ $(-6.3 \mathrm{mmHg})$ for the fixed combination, dorzolamide, and timolol groups, respectively. ${ }^{9}$

The dorzolamide-timolol fixed combination therapy dosed twice daily was also compared with monotherapy with either dorzolamide hydrochloride $2 \% 3$ times daily or timolol maleate $0.5 \%$ twice daily in patients whose IOP was not sufficiently controlled on timolol maleate $0.5 \%$ twice daily alone. In a parallel, randomized, 3-month, multicenter clinical trial, patients who were not responding well to timolol maleate $0.5 \%$ monotherapy were treated with a 3 -week run-in of timolol maleate $0.5 \%$ twice daily and then randomized to receive either the dorzolamide-timolol fixed combination therapy twice daily, timolol maleate $0.5 \%$ monotherapy twice daily, or dorzolamide hydrochloride $2 \%$ monotherapy 3 times daily. The dorzolamide-timolol fixed combination therapy was numerically better at all study time points providing additional IOP-lowering effect compared with its individual components and was statistically superior to its individual components at all time points except for month 2 , hour 0 versus timolol maleate $0.5 \%$ monotherapy and month 2 , hour 2 compared with dorzolamide hydrochloride $2 \%$ monotherapy. ${ }^{28}$

\section{Comparisons with concomitant administration of its components dorzolamide hydrochloride $2 \%$ plus timolol maleate $0.5 \%$}

The efficacy of the dorzolamide-timolol fixed combination (dorzolamide-timolol dosed twice daily) was also found to be comparable to the IOP-lowering effect of its individual components when administered concomitantly (dorzolamide hydrochloride $2 \% 3$ times daily plus timolol maleate $0.5 \%$ twice daily). ${ }^{11,36,37}$ A statistically significant additional IOP reduction was observed in 1study in which the dorzolamidetimolol fixed combination therapy was used as a replacement therapy for patients who were being treated with both a beta blocker and dorzolamide. ${ }^{36}$
In a multicenter, randomized, parallel, 3-month clinical trial with a 1-year open label extension, the IOP-lowering effects of the dorzolamide-timolol fixed combination were found to be comparable to those of the concomitant administration of its components (dorzolamide hydrochloride $2 \%$ plus timolol maleate $0.5 \%$ ) and these effects were maintained for up to 1 year. When compared with the baseline 2-week timolol maleate $0.5 \%$ run-in treatment period, the dorzolamide-timolol fixed combination therapy reduced IOP by approximately $14 \%$ at hour 0 (just before the morning does), $20 \%$ at hour 2 , and $15 \%$ at hour 8 during 3 months of treatment. At this same time point, the IOP-lowering effect of concomitant therapy with dorzolamide hydrochloride $2 \%$ and timolol maleate $0.5 \%$ was approximately $16 \%, 20 \%$, and $17 \%$ at hours 0,2 , and 8 , respectively. At hours 0,2 , and 8 , the authors found that there was $>97 \%$ confidence that treatment with dorzolamide-timolol fixed combination was equivalent to concomitant administration of its components. During the 1 year open-label extension, the reductions in IOP seen at the 3-month timeframe were maintained, the mean IOP reduction ranging from $14 \%$ to $15 \%$ at hour 0 and from $20 \%$ to $21 \%$ at hour $2 .^{11}$

Comparison of the efficacy of the dorzolamide-timolol fixed combination therapy dosed twice daily with the concomitant administration of its components, dorzolamide hydrochloride $2 \%$ twice daily and timolol maleate $0.5 \%$ twice daily, was also studied in a randomized, parallel, multicenter, 3-month clinical trial in patients who had been treated with a 2-week run-in period of timolol maleate $0.5 \%$ monotherapy. These results showed that compared with the timolol maleate $0.5 \%$ monotherapy baseline, additional IOP-lowering of $16 \%$ was observed at trough (hour 0) and 22\% at peak (hour 2) at the 3-month timeframe in both the concomitant therapy and fixed combination therapy groups. These results were clinically and statistically equivalent, extremely small point differences (concomitant IOP minus fixed combination IOP) of $0.01 \mathrm{mmHg}$ at trough (hour 0 ) and $0.08 \mathrm{mmHg}$ at peak (hour 2) being observed in this study. ${ }^{37}$

A prospective, randomized, multicenter, parallel clinical trial and a prospective, nonrandomized comparative replacement study were both conducted by the same group of investigators. ${ }^{36}$ The results of the randomized, parallel study indicated that the dorzolamide-timolol fixed combination therapy was as effective as the concomitant administration of its components at lowering IOP. However, in the replacement comparative study, the fixed combination therapy showed a statistically significant additional reduction in IOP. 
In the randomized, parallel study patients were randomized to receive either dorzolamide-timolol fixed combination therapy or a topical carbonic anhydrase inhibitor (CAI) and nonselective beta blocker after a 1-month run-in period using the separate components and were treated on the randomized therapy for 1 month. Mean baseline IOPs were $18.4 \mathrm{mmHg}$ (peak) and $21.0 \mathrm{mmHg}$ (trough) in the dorzolamide-timolol group and $17.6 \mathrm{mmHg}$ (peak) and $19.8 \mathrm{mmHg}$ (trough) in the concomitant therapy group. The percentage change in IOP was $-3.2 \%$ at peak and $-6.5 \%$ at trough for the dorzolamidetimolol fixed combination therapy group and $-0.3 \%$ at peak and $-3.2 \%$ at trough for the concomitant therapy group. These differences between peak and trough IOP values were not statistically significant. ${ }^{36}$

In the replacement therapy study, glaucoma patients who were using a nonselective beta blocker and dorzolamide hydrochloride $2 \%$ were changed to the fixed combination dorzolamide-timolol therapy for 1 month. Mean baseline IOP measured before switching to the replacement therapy with dorzolamide-timolol was $19.4 \mathrm{mmHg}$ and after 4 weeks of treatment on the replacement therapy, a significant additional IOP reduction of $-1.7 \mathrm{mmHg}(-8.8 \%)$ was observed $(P<0.0001), 81 \%$ of eyes overall having equal or lower IOP on the fixed combination dorzolamide-timolol therapy compared with the concomitant therapy. ${ }^{36}$

\section{Comparison with bimatoprost $0.03 \%$ monotherapy}

In a large multicenter study in patients whose IOP was uncontrolled with timolol maleate $0.5 \%$ monotherapy, the IOP-lowering effects of bimatoprost $0.03 \%$ monotherapy were more consistent and significantly greater than those of the fixed combination dorzolamide-timolol therapy. ${ }^{29}$ In a separate and smaller 3-center crossover study, the results indicated that the IOP-lowering effects of these 2 therapies were statistically similar in patients with glaucoma or $\mathrm{OH}$ who were randomized after a washout period. ${ }^{30}$

A 3-month, randomized, multicenter, parallel study was conducted to compare the dorzolamide-timolol fixed combination therapy dosed twice daily against bimatoprost $0.03 \%$ monotherapy dosed once daily in patients with glaucoma or $\mathrm{OH}$ who had IOP of $\geq 22 \mathrm{mmHg}$ despite treatment with timolol maleate $0.5 \%$ monotherapy. All study subjects were washed out of any ocular hypotensive except for timolol maleate $0.5 \%$ and then treated with timolol maleate $0.5 \%$ monotherapy for at least 2 weeks prior to the baseline study visit. At the 3-month timeframe bimatoprost $0.03 \%$ monotherapy lowered mean IOP by $6.8 \mathrm{mmHg}$ whereas the dorzolamide-timolol fixed combination therapy lowered mean IOP by $5.0 \mathrm{mmHg}(P<0.001)$. Also, the percentage of patients achieving target IOP measurements of $\leq 13 \mathrm{mmHg}$ through $\leq 16 \mathrm{mmHg}$ in $1 \mathrm{mmHg}$ increments at the 0800 hours data point for the 3 month visit were all statistically significantly higher (all more than twice as high) for the bimatoprost monotherapy group compared with the dorzolamidetimolol fixed combination therapy group. The percentage of patients achieving target IOP measurements of $\leq 17 \mathrm{mmHg}$ through $\leq 20 \mathrm{mmHg}$ in $1 \mathrm{mmHg}$ increments at the same timeframe were all higher for the bimatoprost monotherapy group but were not statistically significantly higher than the dorzolamide-timolol fixed combination therapy group. ${ }^{29}$

A 3-center, randomized, crossover comparison study designed with a 4-week washout period followed by two 8-week treatment periods was conducted, with diurnal IOP measurements taken at 0800,1000 , and 1600 hours. The diurnal untreated baseline IOP was $24.8 \mathrm{mmHg}$ and on the last day of treatment the mean diurnal IOP was $17.4 \mathrm{mmHg}$ for the bimatoprost monotherapy group and $18.1 \mathrm{mmHg}$ for the dorzolamide-timolol fixed combination therapy group. These data showed that the individual time points for IOPs were not statistically different between the 2 treatment groups. ${ }^{30}$

\section{Comparison with latanoprost $0.005 \%$ monotherapy}

Compared with latanoprost $0.005 \%$ monotherapy dosed once daily, the dorzolamide-timolol fixed combination dosed twice daily was found to be equally effective at lowering IOP in parallel studies ${ }^{32,33}$ enrolling patients with $\mathrm{OAG}$ or $\mathrm{OH}$, more effective at IOP reduction in a parallel study ${ }^{34}$ enrolling patients with pseudoexfoliation glaucoma, and less effective as an ocular hypotensive regimen in a crossover study ${ }^{31}$ enrolling patients with POAG whose $\mathrm{OH}$ was uncontrolled with beta blocker therapy.

Two parallel, randomized, 3-month multicenter clinical trials, one in the US and the other in Europe/Israel, were conducted in order to compare the dorzolamide-timolol fixed combination therapy dosed twice daily versus latanoprost $0.005 \%$ monotherapy dosed once daily. Patients with $\mathrm{OH}$ or $\mathrm{OAG}$ were washed out of their usual ocular hypotensive medications and then those with a baseline IOP $\geq 24 \mathrm{mmHg}$ in at least 1 eye were randomized to either the dorzolamide-timolol fixed combination group or the latanoprost monotherapy group. The mean diurnal IOP (mean of measurements made at 0800, 1000, 1400, and 1600 hours) was used to assess efficacy. In the US study, the mean daytime diurnal IOP measurements were $26.1 \mathrm{mmHg}$ 
at baseline and $18.9 \mathrm{mmHg}$ at 3 months in the dorzolamidetimolol fixed combination group versus $25.6 \mathrm{mmHg}$ at baseline and $18.4 \mathrm{mmHg}$ at 3 months in the latanoprost group. In the Europe/Israel study, the mean diurnal IOP measurements were $25.3 \mathrm{mmHg}$ at baseline and $17.4 \mathrm{mmHg}$ at 3 months in the dorzolamide-timolol fixed combination group versus $24.7 \mathrm{mmHg}$ at baseline and $17.5 \mathrm{mmHg}$ at 3 months in the latanoprost monotherapy group. At the 3-month timeframe the difference between treatments in mean IOP change was $-0.04 \mathrm{mmHg}$ (95\% confidence interval [CI] -0.85 , $0.77 \mathrm{mmHg})$ in the US study and $-0.57 \mathrm{mmHg}(95 \%$ $\mathrm{CI}-1.31,0.16 \mathrm{mmHg}$ ) in the Europe/Israel study, showing that the dorzolamide-timolol fixed combination therapy was equally effective at lowering IOP as the latanoprost $0.005 \%$ therapy. ${ }^{32}$

A randomized, prospective, crossover study was conducted at 2 centers enrolling patients with POAG or $\mathrm{OH}$ who had undergone a 6-week washout period and were then randomized to be treated with dorzolamide-timolol fixed combination therapy and latanoprost $0.005 \%$ monotherapy in a crossover study. Patients first received 6 months of treatment with either dorzolamide-timolol fixed combination therapy dosed twice daily or latanoprost $0.005 \%$ monotherapy dosed once daily. Both of these therapies demonstrated clinically similar 24-hour IOP-lowering efficacies. After 6 months of treatment with the randomized therapy, patients were then crossed over to the other therapy for an additional 6 months without a washout period separating the 2 treatments. The mean 24-hour IOP was reported after 2 and 6 months of crossover treatment. After 6 months of treatment, 24-hour IOPs were $18.1 \mathrm{mmHg}$ for the dorzolamide-timolol group and 18.3 for the latanoprost group. Compared with 2 months of therapy the dorzolamide-timolol group did not show a significant change in mean 24-hour IOP but the latanoprost group did show an additional reduction of $0.3 \mathrm{mmHg}(P=0.01) .{ }^{33}$

\section{Comparison with travoprost $0.004 \%$ monotherapy}

The IOP-lowering effects of dorzolamide-timolol fixed combination therapy were shown to be both better ${ }^{34}$ and worse $^{31,35}$ than the efficacy of travoprost $0.004 \%$ monotherapy in 3 small, single-center studies.

A randomized, parallel, 6-week, single-center study in patients with $\mathrm{OAG}$ or $\mathrm{OH}$ found that fixed combination therapy with dorzolamide-timolol dosed twice daily was less efficacious than monotherapy with travoprost $0.004 \%$ dosed once daily. IOP reduction and percentage of IOP reduction were compared for measurements made at 0800 ,
1200, 1600, and 2000 hours. Mean average IOP reductions from baseline were $-7.5 \mathrm{mmHg}$ and $-7.1 \mathrm{mmHg}$ at 3 and 6 weeks, respectively, for the travoprost monotherapy group and $-4.8 \mathrm{mmHg}$ and $-4.5 \mathrm{mmHg}$ at 3 and 6 weeks, respectively, for the dorzolamide-timolol fixed combination therapy group. The better mean diurnal IOP reduction seen in the patients receiving the travoprost $0.004 \%$ monotherapy compared with those patients receiving the dorzolamidetimolol fixed combination therapy was statistically significant at both follow-up time points $(P<0.01) .{ }^{35}$

\section{Comparison with either latanoprost $0.005 \%$ monotherapy or travoprost $0.004 \%$ monotherapy in the same trial}

Two studies mentioned previously are summarized separately in this section because they were designed to compare fixed combination dorzolamide-timolol therapy with either latanoprost $0.005 \%$ monotherapy or travoprost $0.004 \%$ monotherapy in the same clinical trial. ${ }^{31,34}$ The IOP-lowering effects of fixed combination dorzolamide-timolol therapy were found to be better than both of the prostaglandin derivatives in patients with pseudoexfoliation glaucoma in one study ${ }^{34}$ but worse than the prostaglandin derivatives in patients with POAG and $\mathrm{OH}$ in another study. ${ }^{31}$

The first of these studies was a randomized, prospective trial in which 50 patients with pseudoexfoliation glaucoma were randomized to receive 6 months of either dorzolamidetimolol fixed combination therapy or monotherapy with either latanoprost $0.005 \%$ or travoprost $0.004 \%$. All treatments considerably reduced the IOP in these patients throughout the 6 months. In the latanoprost group the mean IOP reduction at the 6-month timeframe was $-8.2 \mathrm{mmHg}$, compared with a mean IOP reduction of $-9.3 \mathrm{mmHg}$ in the travoprost group and a mean IOP reduction of $-11.5 \mathrm{mmHg}$ in the dorzolamide-timolol group. A comparison of these groups showed that dorzolamide-timolol fixed combination therapy was more effective than either latanoprost $0.005 \%$ or travoprost $0.004 \%$ monotherapy in lowering IOP $(P<0.05)$ in these patients with pseudoexfoliation glaucoma and that there was no difference between the prostaglandin derivatives. ${ }^{34}$

The second trial was a prospective, randomized, crossover, single-center study in patients having POAG and OH not controlled with beta blocker therapy. Patients received sequential 3 -month courses of monotherapy with latanoprost $0.005 \%$, monotherapy with travoprost $0.004 \%$, or fixed combination therapy with dorzolamide-timolol for the initial therapy. During the crossover period, the selection of the treatment was randomized. The fixed combination dorzolamide-timolol 
was less effective in reducng IOP $(-14.3 \%$ reduction) than the latanoprost $0.005 \%$ monotherapy $(-22.1 \%$ reduction $)$ or the travoprost $0.004 \%$ monotherapy ( $-18.4 \%$ reduction). The IOP-lowering effects were comparable for the 2 prostaglandin derivatives and superior to the effect of the dorzolamidetimolol fixed combination therapy. A selection bias against timolol maleate $0.5 \%$ weakened this study, as patients were enrolled who were already known to respond inadequately to beta blocker therapy prior to study enrollment. ${ }^{31}$

\section{Comparison with concomitant administration of brimonidine tartrate $0.2 \%$ plus timolol maleate $0.5 \%$}

The efficacy of the dorzolamide-timolol fixed combination therapy and the concomitant administration of brimonidine tartrate $0.2 \%$ plus timolol maleate $0.5 \%$ were found to be comparable. ${ }^{38,39}$ A 6-month, randomized, parallel, multicenter clinical trial was conducted in order to compare the efficacy of the fixed combination dorzolamide-timolol dosed twice daily with concomitant administration of brimonidine tartrate $0.2 \%$ plus timolol maleate $0.5 \%$ each dosed twice daily in patients with glaucoma or $\mathrm{OH}$ after an open-label 3-week timolol maleate $0.5 \%$ monotherapy run-in period. At the 3-month timeframe, hour 0 , the dorzolamide-timolol group had a change in IOP of $-3.66 \mathrm{mmHg}$ versus $-4.15 \mathrm{mmHg}$ for the brimonidine plus timolol group, with a statistically significant treatment difference of $0.49 \mathrm{mmHg}$. At month 3 , hour 2, the dorzolamide-timolol group had an adjusted mean change in IOP of $-5.04 \mathrm{mmHg}$ compared with $-5.41 \mathrm{mmHg}$ for the brimonidine plus timolol group, with a statistically comparable treatment difference of $0.36 \mathrm{mmHg}$. At all other timeframes the 2 treatment groups were statistically comparable, the $95 \%$ CIs of the treatment differences being within $\pm 1.5 \mathrm{mmHg} .{ }^{38}$

In another study, the IOP-lowering effects of dorzolamidetimolol fixed combination therapy dosed twice daily was found to be comparable to concomitant administration of brimonidine tartrate $0.2 \%$ plus timolol maleate $0.5 \%$ dosed twice daily at 3 of the 4 time points measured. ${ }^{39}$ A 3-month randomized, parallel, multicenter clinical trial was conducted enrolling patients with POAG, pseudoexfoliative glaucoma, or pigmentary glaucoma who were randomized to the 2 treatment groups after a 3-week run-in period of timolol maleate $0.5 \%$ monotherapy if their peak IOP was $\geq 22 \mathrm{mmHg}$. At the month 3 trough (hour 0 ) and at both month 1 time points, the $95 \%$ CIs of the treatment differences were within the prespecified statistical boundary of $\pm 1.5 \mathrm{mmHg}$. However, at the month 3 , hour 2 time point, the 2 treatments were not comparable. The brimonidine plus timolol group had a slightly higher mean reduction in IOP $(-5.27 \mathrm{mmHg})$ over the dorzolamide-timolol treatment group $(-4.30 \mathrm{mmHg})$ with a treatment difference of $0.97 \mathrm{mmHg}$ and a $95 \%$ CI whose upper limit was beyond the $\pm 1.5 \mathrm{mmHg}$ used to demonstrate statistical comparability. ${ }^{39}$

\section{Comparison with concomitant administration of brimonidine tartrate $0.2 \%$ plus latanoprost $0.005 \%$}

The concomitant administration of brimonidine tartrate $0.2 \%$ plus latanoprost $0.005 \%$ was found to provide superior IOP control in patients with glaucoma and $\mathrm{OH}$ compared with the dorzolamide-timolol fixed combination therapy in 2 randomized, parallel, multicenter clinical studies, one lasting 12 weeks and the other 3 months. The mean IOP reduction at each visit was significantly greater in the patients treated with the brimonidine tartrate $0.2 \%$ plus latanoprost $0.005 \%$ concomitant therapy at each follow-up visit in both clinical trials. In the first study, the mean IOP reduction at peak drug effect at the 6-week visit was $-9.2 \mathrm{mmHg}$ for the brimonidine plus latanoprost group and $-6.7 \mathrm{mmHg}$ for the dorzolamide-timolol group $(P=0.024)$. At the 12 -week visit, IOP reductions were $-9.0 \mathrm{mmHg}$ and $-6.5 \mathrm{mmHg}$ for the brimonidine plus latanoprost and dorzolamide-timolol groups, respectively $(P=0.044)$. In the second study, at the 1 -month visit, the mean IOP reduction was $-10.6 \mathrm{mmHg}$ for the brimonidine plus latanoprost group and $-6.3 \mathrm{mmHg}$ for the dorzolamide-timolol group $(P=0.001)$. At the 3 -month visit, IOP reductions were $-9.1 \mathrm{mmHg}$ and $-6.6 \mathrm{mmHg}$ for the brimonidine plus latanoprost group and the dorzolamidetimolol group, respectively $(P=0.047){ }^{40}$

\section{Comparison with fixed combination therapy with latanoprost $0.005 \%$-timolol maleate $0.5 \%$}

Fixed combination therapy with latanoprost-timolol was found to be slightly more effective than the dorzolamidetimolol fixed combination therapy in reducing mean diurnal IOP in one study involving patients with POAG or OH that were not well controlled on monotherapy. ${ }^{43}$ In a crossover study involving patients with POAG or pigment dispersion glaucoma, or $\mathrm{OH}$ that had been treated with a run-in period of timolol maleate $0.5 \%$, fixed combination therapy with latanoprost-timolol was found to be not statistically different 
from the dorzolamide-timolol fixed combination therapy. ${ }^{42}$ In another crossover single-center study involving patients with POAG or $\mathrm{OH}$ who had been treated with a run-in period of timolol maleate $0.5 \%$, the dorzolamide-timolol and latanoprost-timolol fixed combination therapies were found to be statistically similar. ${ }^{41}$

Patients with elevated IOP due to POAG or $\mathrm{OH}$ whose IOP was insufficiently responsive to monotherapy, defined as those patients whose IOP remained $>20 \mathrm{mmHg}$ on 1 ocular hypotensive medication, were enrolled in a 3-month, randomized, parallel, multicenter clinical study comparing 2 fixed combination therapies, dorzolamide-timolol dosed twice daily or latanoprost-timolol dosed once daily. Patients were randomized at the baseline visit, which was scheduled after a washout period that varied depending on the drug class of the monotherapy that was used before enrollment. Mean diurnal IOPs were similar at baseline and mean reductions in IOP were $-9.4 \mathrm{mmHg}$ in the latanoprost-timolol group and $-8.4 \mathrm{mmHg}$ in the dorzolamide-timolol group at the 3 -month timeframe. The mean difference in IOP reduction between the 2 treatment groups was $1.0 \mathrm{mmHg}$, a $95 \% \mathrm{CI}$ of 0.31 to $1.69(P=0.005)$ showing statistically significantly more favorable results in the latanoprost-timolol group. ${ }^{43}$

A randomized, crossover comparison study was conducted at 2 centers to compare the efficacy of dorzolamidetimolol fixed combination therapy dosed twice daily versus the fixed combination of latanoprost-timolol dosed once daily. Patients enrolled in this study had POAG or $\mathrm{OH}$ and were started on a 4-week run-in period of timolol maleate $0.5 \%$ monotherapy. Then they were randomized to receive 1 of the 2 fixed combination therapies being studied for an 8 -week period. Timolol maleate $0.5 \%$ monotherapy was used for another for an 8-week period, and then the groups were treated with the other fixed combination therapy for an 8 -week period (the crossover therapy period). The diurnal IOP was measured every 2 hours from 0800 to 2000 hours and statistical analysis was performed on the 8 -week data. The mean diurnal IOP was $17.3 \mathrm{mmHg}$ for latanoprost-timolol and $17.0 \mathrm{mmHg}$ for dorzolamide-timolol, showing no statistical difference $(P=0.36)$ between the 2 fixed combination therapies. $^{42}$

A prospective, randomized, single-center, crossover clinical study was conducted in patients with POAG or $\mathrm{OH}$ who had been treated with a 6 -week run-in period of timolol maleate $0.5 \%$ monotherapy. After the run-in period patients were randomized to receive dorzolamide-timolol dosed twice daily or latanoprost-timolol dosed once daily plus a placebo of artificial tears for the second daily dose. Patients were treated with the randomized fixed combination therapy for 6 weeks then were switched to the other fixed combination therapy (the crossover therapy period) for another 6 weeks without the use of a washout period. The mean diurnal IOP was $19.5 \mathrm{mmHg}$ for the dorzolamide-timolol group and $18.9 \mathrm{mmHg}$ for the latanoprost-timolol group with no significant difference found between these treatments at any time point. ${ }^{41}$

A prospective, randomized, single-masked, multicenter study of patients with POAG and $\mathrm{OH}$ who did not respond sufficiently to beta blocker therapy alone demonstrated noninferiority of either fixed combinations of dorzolamidetimolol or latanoprost-timolol after 4 and 12 weeks of treatment. They did find, however, that a higher percentage of patients treated with the latanoprost-timolol combination achieved $\mathrm{IOP} \leq 16 \mathrm{mmHg} .^{48}$

\section{Comparison with fixed combination therapy with travoprost $0.004 \%$-timolol maleate $0.5 \%$}

A prospective, multicenter, double-masked trial randomized 319 patients to receive a fixed combination of either travoprost-timolol once daily in the morning or dorzolamidetimolol twice daily. The travoprost-timolol group had a significantly lower mean diurnal IOP than the dorzolamidetimolol group $(16.5 \mathrm{mmHg} \pm 0.23$ vs $17.3 \mathrm{mmHg} \pm 0.23$; $P=0.011)$. Additionally, the travoprost-timolol combination achieved greater mean IOP reductions from baseline $(35.3 \%$ to $38.5 \%$ ) than dorzolamide-timolol (32.5\% to $34.5 \%){ }^{49}$

\section{Comparison with fixed combination therapy with brimonidine tartrate $0.2 \%$-timolol maleate $0.5 \%$}

In 2 large multicenter clinical studies, the efficacy of dorzolamide-timolol fixed combination therapy was found to be both worse ${ }^{45}$ than and comparable $\mathrm{e}^{44,45}$ to the IOP-lowering effect of fixed combination therapy with brimonidine-timolol in patients with POAG or OH. The efficacy of fixed combinations of either dorzolamide-timolol dosed twice daily or brimonidine-timolol dosed twice daily was evaluated when used as monotherapy or as adjunctive therapy to a prostaglandin analog in patients with POAG or $\mathrm{OH}$ in a randomized, 3-month, parallel, multicenter clinical trial. Fixed combination therapy with dorzolamide-timolol provided the same IOP-lowering effect as brimonidine-timolol fixed 
combination therapy when these were used as adjunctive therapy to a prostaglandin analog (eg, bimatoprost, latanoprost, or travoprost) in one study enrolling patients with POAG or $\mathrm{OH}$. In this study the patients who were not on a prostaglandin analog had a statistically significantly worse IOP-lowering effect from dorzolamide-timolol than from brimonidine-timolol when either of these fixed combination therapies was used as the only ocular hypotensive. At the 3-month timeframe, the mean reduction from baseline IOP for patients who were not on a prostaglandin analog was $-6.7 \mathrm{mmHg}$ for dorzolamide-timolol monotherapy compared with -7.7 for brimonidine-timolol monotherapy $(P=0.040)$. The mean reduction from baseline of patients for whom the fixed combination therapy was an adjunct to a prostaglandin analog was $-5.2 \mathrm{mmHg}$ for patients on dorzolamide-timolol therapy compared with $-6.9 \mathrm{mmHg}$ for patients on brimonidine-timolol therapy $(P=0.213) .{ }^{45}$

In a separate prospective, randomized, crossover comparison, multicenter clinical study, the efficacy of fixed combination therapy with dorzolamide-timolol dosed twice daily was similar to that of brimonidine-timolol dosed twice daily in patients with POAG or OH. Patients were randomized at the baseline visit which was scheduled after a washout period that varied depending on the drug class of the monotherapy used before enrollment. After the appropriate washout period, patients were randomized to receive either dorzolamide-timolol or brimonidine-timolol for 4 weeks, then the patients underwent a 4-week washout period before they were started on the other fixed combination therapy for another 4 weeks (the crossover therapy period), with IOP measured at 0800, 1200, and 1600 hours. The mean diurnal IOP at baseline for all patients was $22.9 \mathrm{mmHg}$ and both fixed combination therapies significantly reduced the mean diurnal IOP. The mean diurnal IOP at the 4-week timeframe was $15.0 \mathrm{mmHg}(-7.8 \mathrm{mmHg}$ mean IOP reduction) for the brimonidine-timolol therapy and $15.4 \mathrm{mmHg}(-7.4 \mathrm{mmHg}$ mean IOP reduction) for the dorzolamide-timolol therapy $(P=0.510$ for mean diurnal IOP and $P=0.430$ for mean IOP reduction). ${ }^{44}$

\section{Other efficacy studies}

The IOP-lowering effect of dorzolamide-timolol fixed combination therapy was studied retrospectively in a population of glaucoma patients who had not responded to prostaglandin analog therapy and was found to significantly reduce the IOP in this patient population whose major diagnosis was pseudoexfoliation glaucoma (58\% of patients in the study). A retrospective medical record review identified glaucoma patients who were nonresponders to prostaglandin analogs, defined as those having an IOP-lowering effect less than $15 \%$ compared with their baseline IOP measurements, and had subsequently been dosed with dorzolamide-timolol fixed combination therapy. Twelve-hour diurnal curves were prepared for each of the therapy regimens from the available medical records of the chosen patients. The authors found that the dorzolamide-timolol fixed combination therapy significantly reduced IOP in patients overall, from $25.4 \mathrm{mmHg}$ down to $20.2 \mathrm{mmHg}(P<0.0001)$. Dorzolamide-timolol was also found to reduce the mean IOP fluctuations over the 12 hours from $8.6 \mathrm{mmHg}$ down to $4.3 \mathrm{mmHg}(P<0.0001) .{ }^{46}$

Prophylactic treatment with dorzolamide-timolol fixed combination therapy was more effective than brimonidine tartrate $0.2 \%$ monotherapy in reducing the IOP in patients undergoing phacoemulsification cataract surgery. In this prospective, randomized, single-center study patients were randomly assigned to 3 treatment groups: 1 drop of dorzolamide-timolol, 1 drop of brimonidine tartrate $0.2 \%$, or no ocular hypotensive treatment (control group). The IOP was measured at 6 hours and 24 hours after surgery. At both time points the IOPs after surgery were lower in the dorzolamidetimolol treatment group. Six hours after surgery, the mean IOP was $16.3 \mathrm{mmHg}$ in the dorzolamide-timolol group, $20.6 \mathrm{mmHg}$ in the brimonidine group, and $24.6 \mathrm{mmHg}$ in the control group. At 24 hours after surgery, the mean IOP was found to be higher in the control group (19.8 $\mathrm{mmHg}$ ) than in the dorzolamide-timolol group $(14.1 \mathrm{mmHg})$ and the brimonidine group $(17.5 \mathrm{mmHg}){ }^{47}$

A prospective, 4-week trial in patients who demonstrated at least $15 \%$ IOP reduction following a minimum of 15 days' therapy with latanoprost and whose IOP was still considered higher than the clinically determined target level randomized 1 eye to additive treatment with fixed combination dorzolamide-timolol. The fellow was used as a monotherapy control. Starting from similar baselines, mean diurnal IOP levels in the add-on group were $7.4 \%$ lower than those of the monotherapy group $(P=0.01) .{ }^{50}$

An open-label, 12-week Canadian study evaluated patients previously untreated for $\mathrm{OAG}$ or $\mathrm{OH}$. All patients were initially treated with fixed combination dorzolamidetimolol. If a target of $5 \mathrm{mmHg}$ or at least $20 \%$ IOP reduction from baseline was not met by 6 weeks, additional therapy with latanoprost was begun. Of 164 enrolled patients, $28(17.1 \%)$ were changed to combination therapy with dorzolamide-timolol and latanoprost. Between weeks 6 and 12, the dorzolamide-timolol alone group maintained IOP control within the target range, and the group with the added 
prostaglandin experienced additional $6.3 \mathrm{mmHg}(22 \%)$ IOP lowering. At the completion of the study, the dorzolamidetimolol arm had a $12.2 \mathrm{mmHg}(40.4 \%)$ decrease from baseline IOP, whereas the dorzolamide-timolol plus latanoprost group was $13.4 \mathrm{mmHg}(39.7 \%)$ lower than baseline. ${ }^{51}$ Therefore, if a $20 \%$ IOP reduction cannot be achieved with first-line dorzolamide "monotherapy", addition of a prostaglandin is likely to bring the IOP within below the target level.

\section{Safety and tolerability Overview of safety data}

The use of dorzolamide-timolol fixed combination therapy has been shown to be well tolerated by patients, and the adverse event profile mirrors those of its individual components. No additional tolerability issues have been identified that are specific to this fixed combination formulation. ${ }^{18,52}$ The tolerability of dorzolamide-timolol fixed combination therapy was shown to be comparable to that of timolol maleate $0.5 \%$, latanoprost $0.005 \%$, and the fixed combination of latanoprost-timolol in a large (3481 patients) multicenter clinical study conducted at 9 centers in The Netherlands where these 4 glaucoma medications were the most frequently prescribed therapies. Most patients (79\%) in this study were satisfied with their glaucoma medications and only $9 \%$ of patients discontinued their eye drops due to adverse events or side effects. ${ }^{53}$

\section{Ocular and local adverse events}

\section{Burning and stinging}

The most common adverse events typically reported by up to $30 \%$ of patients are ocular and local effects including mild to moderate transient burning or stinging sensation, which is likely due to the dorzolamide hydrochloride $2 \%$ component, and dysgeusia (taste perversion reported as bitter, sour, or unusual taste). ${ }^{18,52}$ These data are noted in the manufacturer's product labeling which includes results from their original clinical studies and has also been reproduced in other large comparative trials where the incidences of drug-related ocular burning or stinging sensation with dorzolamidetimolol were higher than those with other ocular hypotensive medications. ${ }^{18}$ In these large comparative studies, other adverse events were reported, some of incidence rates being statistically significantly different between the dorzolamidetimolol fixed combination therapy and the comparator therapy. Ocular burning and stinging was more frequent with dorzolamide-timolol than with brimonidine-timolol fixed combination in 2 studies $\left(P=0.027^{44}\right.$ and $\left.P<0.001^{45}\right)$, concomitant administration of brimonidine tartrate $0.2 \%$ plus timolol maleate $0.5 \%(P<0.001),{ }^{38}$ timolol maleate $0.5 \%$ in 2 studies $\left(P=0.008^{9}\right.$ and $\left.P<0.001^{28}\right)$, bimatoprost $0.03 \%(P=0.0005),{ }^{30}$ or latanoprost $0.005 \%$ in 2 studies $\left(P<0.001^{33}\right.$ and $\left.P<0.05^{32}\right)$.

\section{Eye pain}

When comparing dorzolamide-timolol against latanoprosttimolol, transient eye pain that occurred after drug administration and was not long lasting was reported significantly more often $(P=0.034)$ with dorzolamide-timolol recipients (11.7\% of patients) than with latanoprost-timolol recipients ( $4.0 \%$ of patients).$^{43}$ Eye pain was also statistically significantly less in the dorzolamide-timolol therapy group compared with concomitant treatment with its components (dorzolamide hydrochloride $2 \%$ plus timolol maleate $0.5 \%$ ) in one study (299 patients, $P=0.014)^{37}$; however, eyelid pain or discomfort was statistically significantly greater in the dorzolamide-timolol group in another study (242 patients, $P=0.036) \cdot{ }^{11}$

\section{Corneal signs}

All corneal signs $(P=0.011)$ and specifically superficial punctate keratitis $(P=0.005)$ were statistically significantly lower in the dorzolamide-timolol fixed combination therapy compared with concomitant therapy with its components (dorzolamide hydrochloride $2 \%$ plus timolol maleate $0.5 \%) .{ }^{37}$ In vitro study of the effects of dorzolamide $2 \%$-timolol $0.5 \%$ fixed combination and brimonidine $0.2 \%$-timolol $0.5 \%$ fixed combination on tissue culture plates with human conjunctival and corneal epithelial cells demonstrated a significant reduction in live cells exposed to dorzolamide-timolol compared with brimonidine-timolol for both the conjunctival and corneal tissue cultures. ${ }^{54}$ These findings may be relevant for patients receiving chronic therapy for glaucoma.

\section{Conjunctivitis}

Conjunctival hyperemia was reported significantly less often by patients treated with dorzolamide-timolol than those receiving either latanoprost $0.005 \%$ or travoprost $0.004 \%$ monotherapy in 2 studies, ${ }^{31,34}$ latanoprost-timolol fixed combination therapy $(P=0.045),{ }^{42}$ or bimatoprost $0.03 \%$ in 2 studies $\left(P=0.009^{29}\right.$ and $\left.P=0.013^{30}\right)$ and was lower but not statistically significantly less frequent compared to brimonidine-timolol fixed combination therapy in one study. ${ }^{44}$ Conjunctivitis was reported significantly less often in the dorzolamide-timolol group than in the dorzolamide 
monotherapy group $(P=0.034) .{ }^{28}$ The side effects of conjunctival hyperemia were also more frequent in another study after latanoprost $0.005 \%$ and travoprost $0.004 \%$ therapy than after the dorzolamide-timolol therapy. ${ }^{31}$

\section{Other effects}

Blurry vision was significantly higher with fixed combination dorzolamide-timolol therapy than with timolol maleate $0.5 \%$ in one study $(P=0.023) .{ }^{9}$ The tolerability profile of dorzolamide-timolol was similar to travoprost $0.004 \%$ monotherapy, ${ }^{35}$ concomitant administration of brimonidine tartrate $0.2 \%$ plus timolol maleate $0.5 \%,{ }^{28}$ and brimonidine tartrate $0.2 \%$ plus latanoprost $0.005 \%$ when dosed concomitantly in another study. ${ }^{18,40}$ In one study, hypertrichosis $(P=0.02)$ and ocular itching $(P=0.004)$ was reported more frequently with latanoprost $0.005 \%$ than with dorzolamide-timolol. ${ }^{33}$ Overall comfort was statistically significantly higher with brimonidine-timolol fixed combination therapy than with dorzolamide-timolol fixed combination therapy $(P=0.014){ }^{45}$

\section{Disturbances of taste}

Bitter taste, dysgeusia, or taste perversion were the most commonly reported nonocular symptoms with the dorzolamide-timolol fixed combination. They had a statistically significantly greater incidence than bimatoprost $0.03 \%$ monotherapy $(P=0.027),{ }^{29}$ travoprost $0.004 \%$ monotherapy $(P=0.0022),{ }^{35}$ timolol maleate $0.5 \%$ monotherapy in 2 studies $\left(P=0.019^{9}\right.$ and $\left.P<0.020^{28}\right)$, latanoprost-timolol fixed combination therapy $(P=0.04),{ }^{42}$ brimonidine-timolol fixed combination therapy $(P<0.001),{ }^{45}$ concomitant therapy with brimonidine tartrate $0.2 \%$ plus timolol maleate $0.5 \%$ in 2 studies $\left(P<0.001^{38}\right.$ and $\left.P<0.001^{39}\right)$, and latanoprost $0.005 \%$ monotherapy in 2 studies $\left(P<0.0002^{33}\right.$ and $\left.P<0.05^{32}\right)$. There were no statistically significant differences for this nonocular symptom compared with the dorzolamide-timolol fixed combination therapy with concomitant administration of brimonidine tartrate $0.2 \%$ plus timolol maleate $0.5 \%{ }^{39}$, monotherapy with either of its components (dorzolamide hydrochloride $2 \%$ or timolol maleate $0.5 \%),{ }^{28}$ or compared with concomitant administration of its components in 2 studies. ${ }^{11,37}$

\section{Systemic adverse events}

Systemic adverse events associated with CAIs include headache, nausea, and urolithiasis, likely due to the dorzolamide hydrochloride $2 \%$ component, as well as bradycardia, cardiac failure, heart block, hypotension, and respiratory symptoms or failure, likely due to the timolol maleate $0.5 \%$ component. Although serious, these events have been reported infrequently during the marketing approval clinical trials and the postmarketing experience..$^{18,52}$

Some of the clinical studies conducted on dorzolamidetimolol fixed combination therapy beyond the marketing approval trials also had reports of systemic adverse events including: allergic reaction $\left(0.7 \%{ }^{38}\right.$ and $\left.1.1 \%{ }^{45}\right)$; benign atrial myxoma $(0.7 \%) ;{ }^{38}$ crystalluria $(0.5 \%) ;{ }^{11}$ dizziness $(1.0 \%) ;{ }^{28}$ dry mouth $(2 \%) ;{ }^{11}$ dyspnea $(0.4 \%) ; ;^{39}$ eye discharge $(2 \%) ;{ }^{11}$ foreign body sensation $(2 \%) ;{ }^{11}$ headache $\left(1.1 \%,{ }^{45} 1.6 \%,{ }^{43}\right.$ and $\left.3 \%{ }^{11}\right)$; fatigue $(1.1 \%),{ }^{45}$ flu $(3.1 \%) ;{ }^{41}$ hyperglycemia $(2 \%) ;{ }^{11}$ lens opacity $(5 \%) ;{ }^{11}$ leukocytosis $(3 \%) ;{ }^{11}$ nausea $(1.0 \%) ;{ }^{28}$ oxaluria $(0.5 \%) ;{ }^{11}$ parathyroid hyperplasia $(0.7 \%) ; ;^{38}$ pneumonia $(0.7 \%) ;{ }^{38}$ traumatic amputation of finger and thumb $(0.7 \%) ;{ }^{38}$ tremor $(1.0 \%) ; ;^{28}$ upper respiratory infection $(6 \%) ;{ }^{11}$ and urolithiais $(2.5 \%) .{ }^{11}$ In one comparative study, headache was reported more frequently in the latanoprost group than in the dorzolamidetimolol group $(P=0.04) .{ }^{33} \mathrm{~A}$ recent case of disseminated skin eruption and severe thrombocytopenia was attributed to treatment with dorzolamide-timolol. The skin rash resolved after stopping the eye drop, but reactivated following challenge with dapsone, suggesting sulphonamide cross-reactivity. ${ }^{55}$

\section{Complete safety profile from marketing approval studies}

The safety of fixed combination dorzolamide-timolol therapy was evaluated in 1035 patients with elevated IOP treated for POAG or $\mathrm{OH}$ as part of the clinical studies required to obtain approval from the FDA to market this ocular hypotensive. ${ }^{52}$ In these studies, approximately 5\% of all patients discontinued therapy because of adverse reactions, dysgeusia or ocular burning or stinging being the most frequently reported adverse events (reported in up to $30 \%$ of patients). Adverse events that were reported in $5 \%$ to $15 \%$ of patients include conjunctival hyperemia, blurred vision, superficial punctate keratitis, and eye itching. Additional adverse events were reported in $1 \%$ to $5 \%$ of patients, including abdominal pain, back pain, blepharitis, bronchitis, cloudy vision, conjunctival discharge, conjunctival edema, conjunctival follicles, conjunctival injection, conjunctivitis, corneal erosion, corneal staining, cortical lens opacity, cough, dizziness, dryness of eyes, dyspepsia, eye debris, eye discharge, eye pain, eye tearing, eyelid edema, eyelid erythema, eyelid exudate/scales, eyelid pain or discomfort, foreign body sensation, glaucomatous 
cupping, headache, hypertension, influenza, lens nucleus coloration, lens opacity, nausea, nuclear lens opacity, pharyngitis, postsubcapsular cataract, sinusitis, upper respiratory infection, urinary tract infection, visual field defect, and vitreous detachment.

The following adverse events occurred either at low incidence $(<1 \%)$ during the clinical trials or have been reported to the manufacturer during the use of dorzolamide-timolol in clinical practice, where these events were reported voluntarily from a population of unknown size and frequency of occurrence cannot be determined precisely by the manufacturer. The manufacturer includes them in their product labeling because of their seriousness, frequency, possible causal connection to dorzolamide-timolol fixed combination therapy, or a combination of these factors: bradycardia, cardiac failure, cerebral vascular accident, chest pain, choroidal detachment following filtration surgery, depression, diarrhea, dry mouth, dyspnea, heart block, hypotension, iridocyclitis, myocardial infarction, nasal congestion, paresthesia, photophobia, respiratory failure, skin rashes, urolithiasis, and vomiting. ${ }^{52}$

\section{Patient-focused perspectives}

The goal of treatment for patients with glaucoma or $\mathrm{OH}$ is to control their IOP down to a level that preserves optic nerve function and stability of their visual fields. This is best achieved if the medication is harmonious with the patient's lifestyle. ${ }^{28}$ As has been discussed previously, patient compliance can affect medication efficacy. Using a fixed combination therapy can enhance patient adherence by simplifying the treatment regimen, improve drug delivery by reducing the washout effect, and limit toxicity by decreasing the preservative burden.

Patient acceptance of medication includes tolerability of the side effects. Fixed combination dorzolamide-timolol carries the potential side effects of both of its component agents. Use may be contraindicated in patients with known cardiovascular disease or chronic obstructive pulmonary disease, and patients need to be counseled on potential adverse effects due to the timolol component's beta-adrenergic blocking mechanism of action. The dorzolamide component is a sulfonamide agent, and its use is limited in the population of patients who have a known sensitivity to this class of drugs. In the preapproval FDA trials, approximately $5 \%$ of patients discontinued therapy because of intolerance/adverse reactions. Dysgeusia and ocular burning or stinging were the most frequently reported adverse events (reported in up to $30 \%$ of patients), and $5 \%$ to $15 \%$ of patients reported conjunctival hyperemia, blurred vision, superficial punctate keratitis, or eye itching. ${ }^{52}$ When the fixed combination dorzolamide-timolol was compared with monotherapy with its 2 components in a 3-month, parallel, randomized clinical study, patients in the dorzolamide monotherapy treatment group and patients in the fixed combination dorzolamidetimolol treatment group both reported a statistically significantly higher rate of burning and stinging sensation (dorzolamide-timolol $=18 \%$, dorzolamide monotherapy $=14 \%$ ) and taste perversion (dorzolamide-timolol $=8 \%$, dorzolamide monotherapy $=10 \%$ ) than patients in the timolol (burning/stinging $=6 \%, P=0.008$ vs dorzolamide-timolol, taste perversion $=1 \%, P=0.019$ vs dorzolamide-timolol) monotherapy treatment group, implicating dorzolamide as the likely offending agent. In this study a significantly greater proportion of patients in the dorzolamide-timolol treatment group discontinued from the study because of adverse effects compared with the timolol treatment group (7\% vs $1 \%, P=0.035){ }^{9}$

When 2 topical ocular medications are administered simultaneously or in close time proximity, the concentration of each is diluted and the excess medication is flushed away through the lacrimal system or down the cheek. This so-called "washout" is reduced by the use of fixed combination formulations which permit both medicines to be instilled in 1 drop with consistent drug concentrations. The reduced number of drops that a patient has to instill also reduces the burden of potentially toxic preservatives to which the eye is exposed. ${ }^{56}$

\section{Conclusions}

The efficacy of the fixed combination dorzolamide-timolol has been shown in controlled clinical studies to be greater than when either of its components is used individually as monotherapy, and it is also comparable to the use of its components concomitantly. Numerous clinical studies show comparable efficacy between the fixed combination dorzolamide-timolol and other topical agents used alone or in combination therapies. The safety profile of the fixed combination dorzolamide-timolol is similar to that of its individual components, and no additional tolerability issues have been identified specifically with this fixed combination therapy.

Patient compliance with their medication regimen is inversely related to the prescribed number of doses per day, and it is well documented that less frequent dosing regimens result in better compliance across a variety of therapeutic classes. The convenience of a fixed combination 
therapy has been shown to increase patient compliance in various studies. The fixed combination dorzolamide-timolol therapy improves patient compliance by reducing the prescribed number of doses per day. Use of fixed combination dorzolamide-timolol also decreases the load of preservatives to which the patients' eyes are exposed and eliminates the effects of having the first instilled drug being diluted or "washed out" by the second instilled drug.

Rising health care costs are a concern for all, and the cost of treating glaucoma constitutes a significant financial load on the health care system. A cost analysis in the US has shown that generic nonselective beta blockers are the most inexpensive class of glaucoma medications, with generic timolol costing US\$150.81 per year. ${ }^{57}$ The concomitant use of a CAI added US\$385.41 per year. Thus concomitant therapy with the 2 components had a combined cost of US\$536.22 per year. This cost analysis used the brand name version of the fixed combination dorzolamide-timolol therapy (US\$697.42 per year) to calculate the costs because the generic version was not available at the time of the study. ${ }^{57}$ The generic version of the fixed combination dorzolamide-timolol is expected to reduce the yearly costs to patients and the health care system.

Thus, the role of fixed combination dorzolamide-timolol can be either as a replacement or adjunct therapy when a patient's IOP is not adequately lowered with either of these 2 medications individually. A limitation to the first-line use of fixed combination dorzolamide-timolol is that in the case of an adverse event or a side effect, identification of the offending component may be difficult. In some cases the fixed combination would need to be discontinued and the individual components administered independently to decipher which agent is to blame. Clinicians are advised to use their best medical judgment in choosing treatment options for their patients, taking into account that an individual patient's results may not exactly mimic the overall patient population results of any particular clinical study presented herein.

\section{Disclosure}

The authors report no proprietary interests or conflicts of interest in any of the products described in this work.

\section{References}

1. An overview of glaucoma. In: Allingham RR, Damji KF, Freedman S, Moroi SE, Shafranov G, Shields MB, editors. Shields' Textbook of Glacuoma. 5th ed. Philadelphia: Lippincott Williams \& Wilkins; 2005:1-2.
2. Folberg R. The Eye. In: Kumar V, Abbas AK, Fausto N, editors. Robbins and Cotran Pathologic Basis of Disease. 7th ed. Philadelphia: Elsevier Saunders; 2005:1421-1447.

3. Leske MC. Open-angle glaucoma - an epidemiologic overview. Ophthalmic Epidemiol. 2007 Jul-Aug;14(4):166-172.

4. Quigley HA, Broman AT. The number of people with glaucoma worldwide in 2010 and 2020. Br J Ophthalmol. 2006;90(3):262-267.

5. Rudnicka AR, Mt-Isa S, Owen CG, Cook DG, Ashby D. Variations in primary open-angle glaucoma prevalence by age, gender, and race: a Bayesian meta-analysis. Invest Ophthalmol Vis Sci. 2006;47(10): 4254-4261.

6. Khouri AS, Realini T, Fechtner RD. Fixed-combination drugs. In: Netland PA, editor. Glaucoma Medical Therapy, Principles and Management. 2nd ed. New York: Oxford University Press; 2008: 139-150.

7. Kass MA, Heuer DK, Higginbotham EJ, et al. The Ocular Hypertension Treatment Study: a randomized trial determines that topical ocular hypotensive medication delays or prevents the onset of primary openangle glaucoma. Arch Ophthalmol. 2002;120(6):701-713; discussion 829-730.

8. Kobelt G. Health economics, economic evaluation, and glaucoma. J Glaucoma. 2002;11(6):531-539.

9. Boyle JE, Ghosh K, Gieser DK, Adamsons IA. A randomized trial comparing the dorzolamide-timolol combination given twice daily to monotherapy with timolol and dorzolamide. Dorzolamide-Timolol Study Group. Ophthalmology. 1998;105(10):1945-1951.

10. Claxton AJ, Cramer J, Pierce C. A systematic review of the associations between dose regimens and medication compliance. Clin Ther. 2001;23(8):1296-1310.

11. Strohmaier K, Snyder E, DuBiner H, Adamsons I. The efficacy and safety of the dorzolamide-timolol combination versus the concomitant administration of its components. Dorzolamide-Timolol Study Group. Ophthalmology. 1998;105(10):1936-1944.

12. Greenberg RN. Overview of patient compliance with medication dosing: a literature review. Clin Ther. 1984;6(5):592-599.

13. Higginbotham EJ. Considerations in glaucoma therapy: fixed combinations versus their component medications. Clin Ophthalmol. 2010; 4:1-9.

14. Ichhpujani P, Katz LJ. Efficacy, safety and tolerability of combination therapy with timolol and dorzolamide in glaucoma and ocular hypertension. Drug, Healthcare and Patient Safety. 2010;2: $73-83$.

15. Razeghinejad MR, Sawchyn AK, Katz LJ. Fixed combinations of dorzolamide-timolol and brimonidine-timolol in the management of glaucoma. Expert Opin Pharmacother. 2010;11(6):959-968.

16. Food and Drug Administration. Generic Drug Roundup: Feb 2009. http:// www.fda.gov/downloads/ForConsumers/ConsumerUpdates/ucm089346. pdf. Published 2009 Feb 2. Accessed 2009 Oct 2.

17. Baiza-Duran LM, Alvarez-Delgado J, Contreras-Rubio AY, et al. The efficacy and safety of two fixed combinations: timolol-dorzolamidebrimonidine versus timolol-dorzolamide. A prospective, randomized, double-masked, multi-center, 6-month clinical trial. Ann Ophthalmol (Skokie). 2009;41(3-4):174-178.

18. Frampton JE, Perry CM. Topical dorzolamide $2 \%$ /timolol $0.5 \%$ ophthalmic solution: a review of its use in the treatment of glaucoma and ocular hypertension. Drugs Aging. 2006;23(12):977-995.

19. Hoffman BB. Adrenoceptor antagonist drugs. In: Katzung BG, editior. Basic and Clinical Pharmacology. New York: McGraw-Hill; 2007: 141-158.

20. Food and Drug Administration. Overview: Dorzolamide Hydrochloride and Timolol Maleate. http://www.accessdata.fda.gov/scripts/cder/drug satfda/ index.cfm? fuseaction=Search. Overview $\&$ DrugName $=$ DORZOL AMIDE\%20HYDROCHLORIDE\%20AND\%20TIMOLOL\%20 MALEATE \&CFID $=50418758 \&$ CFTOKEN $=18 f 5006 \mathrm{a} 032$ ce6b8-B14B17B2-EB11-C82D-B8C8A0BAEEFB9D7B. Updated 2009 Oct 19. Accessed 2009 Oct 19. 
21. Hutnik C, Neima D, Ibrahim F, et al. Tolerability and effectiveness of preservative-free dorzolamide-timolol (preservative-free COSOPT) in patients with open-angle glaucoma or ocular hypertension. Clin Ophthalmol. 2010;4:581-590.

22. Shedden A, Adamsons IA, Getson AJ, et al. Comparison of the efficacy and tolerability of preservative-free and preservative-containing formulations of the dorzolamide/timolol fixed combination (COSOPT) in patients with elevated intraocular pressure in a randomized clinical trial. Graefes Arch Clin Exp Ophthalmol. 2010 May 2. [Epub ahead of print].

23. Azarga [package insert-prescribing information]. Hemel Hempstead, UK: Alcon Laboratories (UK) Ltd.; 2008.

24. Januleviciene I. Brinzolamide $1 \% /$ timolol $0.5 \%$ : safety and efficacy of a new fixed-combination IOP-lowering product for glaucoma. Curr Med Res Opin. 2010;26(11):2575-2578.

25. Mundorf TK, Rauchman SH, Williams RD, Notivol R. A patient preference comparison of Azarga (brinzolamide/timolol fixed combination) vs Cosopt (dorzolamide/timolol fixed combination) in patients with open-angle glaucoma or ocular hypertension. Clin Ophthalmol. 2008;2(3):623-628.

26. Vold SD, Evans RM, Stewart RH, Walters T, Mallick S. A one-week comfort study of BID-dosed brinzolamide $1 \% /$ timolol $0.5 \%$ ophthalmic suspension fixed combination compared to BID-dosed dorzolamide $2 \%$ / timolol $0.5 \%$ ophthalmic solution in patients with open-angle glaucoma or ocular hypertension. J Ocul Pharmacol Ther. 2008;24(6):601-605.

27. Merck Sharp \& Dohme v Alcon. Code of Practice Review. 2010 May: 114-125.

28. Clineschmidt CM, Williams RD, Snyder E, Adamsons IA. A randomized trial in patients inadequately controlled with timolol alone comparing the dorzolamide-timolol combination to monotherapy with timolol or dorzolamide. Dorzolamide-Timolol Combination Study Group. Ophthalmology. 1998;105(10):1952-1959.

29. Coleman AL, Lerner F, Bernstein P, Whitcup SM. A 3-month randomized controlled trial of bimatoprost (LUMIGAN) versus combined timolol and dorzolamide (Cosopt) in patients with glaucoma or ocular hypertension. Ophthalmology. 2003;110(12):2362-2368.

30. Day DG, Sharpe ED, Beischel CJ, Jenkins JN, Stewart JA, Stewart WC. Safety and efficacy of bimatoprost $0.03 \%$ versus timolol maleate $0.5 \%$ / dorzolamide 2\% fixed combination. Eur J Ophthalmol. 2005;15(3) 336-342.

31. Chiselita D, Antohi I, Medvichi R, Danielescu C. Comparative analysis of the efficacy and safety of latanoprost, travoprost and the fixed combination timolol-dorzolamide; a prospective, randomized, masked, cross-over design study. Oftalmologia. 2005;49(3):39-45.

32. Fechtner RD, Airaksinen PJ, Getson AJ, Lines CR, Adamsons IA. Efficacy and tolerability of the dorzolamide $2 \%$ /timolol $0.5 \%$ combination (COSOPT) versus $0.005 \%$ (XALATAN) in the treatment of ocular hypertension or glaucoma: results from two randomized clinical trials. Acta Ophthalmol Scand. 2004;82(1):42-48.

33. Konstas AG, Kozobolis VP, Tsironi S, Makridaki I, Efremova R, Stewart WC. Comparison of the 24-hour intraocular pressure-lowering effects of latanoprost and dorzolamide/timolol fixed combination after 2 and 6 months of treatment. Ophthalmology. 2008;115(1):99-103.

34. Parmaksiz S, Yuksel N, Karabas VL, Ozkan B, Demirci G, Caglar Y. A comparison of travoprost, latanoprost, and the fixed combination of dorzolamide and timolol in patients with pseudoexfoliation glaucoma. Eur J Ophthalmol. 2006;16(1):73-80.

35. Suzuki ER Jr, Franklin LM, da Silva LJ, Figueiredo CR, Netto JA, Batista WD. Comparison of the efficacy and safety of travoprost with a fixed-combination of dorzolamide and timolol in patients with openangle glaucoma or ocular hypertension. Curr Med Res Opin. 2006;22(9): 1799-1805.

36. Francis BA, Du LT, Berke S, Ehrenhaus M, Minckler DS. Comparing the fixed combination dorzolamide-timolol (Cosopt) to concomitant administration of $2 \%$ dorzolamide (Trusopt) and $0.5 \%$ timolol - a randomized controlled trial and a replacement study. J Clin Pharm Ther. 2004;29(4):375-380.
37. Hutzelmann J, Owens S, Shedden A, Adamsons I, Vargas E. Comparison of the safety and efficacy of the fixed combination of dorzolamide/timolol and the concomitant administration of dorzolamide and timolol: a clinical equivalence study. International Clinical Equivalence Study Group. Br J Ophthalmol. 1998;82(11):1249-1253.

38. Sall KN, Greff LJ, Johnson-Pratt LR, et al. Dorzolamide/timolol combination versus concomitant administration of brimonidine and timolol: six-month comparison of efficacy and tolerability. Ophthalmology. 2003;110(3):615-624.

39. Solish AM, DeLucca PT, Cassel DA, Kolodny AH, Hustad CM, Skobieranda F. Dorzolamide/timolol fixed combination versus concomitant administration of brimonidine and timolol in patients with elevated intraocular pressure: a 3-month comparison of efficacy, tolerability, and patient-reported measures. J Glaucoma. 2004;13(2):149-157.

40. Zabriskie N, Netland PA. Comparison of brimonidine/latanoprost and timolol/dorzolamide: two randomized, double-masked, parallel clinical trials. Adv Ther. 2003;20(2):92-100.

41. Cvenkel B, Stewart JA, Nelson LA, Stewart WC. Dorzolamide/timolol fixed combination versus latanoprost/timolol fixed combination in patients with primary open-angle glaucoma or ocular hypertension. Curr Eye Res. 2008;33(2):163-168.

42. Konstas AG, Kozobolis VP, Lallos N, Christodoulakis E, Stewart JA, Stewart WC. Daytime diurnal curve comparison between the fixed combinations of latanoprost $0.005 \% /$ timolol maleate $0.5 \%$ and dorzolamide 2\%/timolol maleate 0.5\%. Eye (Lond). 2004;18(12):1264-1269.

43. Shin DH, Feldman RM, Sheu WP. Efficacy and safety of the fixed combinations latanoprost/timolol versus dorzolamide/timolol in patients with elevated intraocular pressure. Ophthalmology. 2004;111(2):276-282.

44. Arcieri ES, Arcieri RS, Pereira AC, Andreo EG, Finotti IG, Sa Filho WF. Comparing the fixed combination brimonidine-timolol versus fixed combination dorzolamide-timolol in patients with elevated intraocular pressure. Curr Med Res Opin. 2007;23(4):683-689.

45. Nixon DR, Yan DB, Chartrand JP, Piemontesi RL, Simonyi S, Hollander DA. Three-month, randomized, parallel-group comparison of brimonidine-timolol versus dorzolamide-timolol fixed-combination therapy. Curr Med Res Opin. 2009;25(7):1645-1653.

46. Martinez A, Sanchez M. Intraocular pressure lowering effect of dorzolamide/timolol fixed combination in patients with glaucoma who were unresponsive to prostaglandin analogs/prostamides. Curr Med Res Opin. 2007;23(3):595-599.

47. Ozkurt Y, Oral Y, Karacan O, Comez A, Dogan OK. Comparison of the effects of dorzolamide-timolol fixed combination and brimonidine on intraocular pressure after phacoemulsification surgery. Eye Contact Lens. 2008;34(1):21-23.

48. Miglior S, Grunden JW, Kwok K. Efficacy and safety of fixed combinations of latanoprost/timolol and dorzolamide/timolol in open-angle glaucoma or ocular hypertension. Eye (Lond). 2010;24(7):1234-1242.

49. Teus MA, Miglior S, Laganovska G, et al. Efficacy and safety of travoprost/timolol vs dorzolamide/timolol in patients with open-angle glaucoma or ocular hypertension. Clin Ophthalmol. 2009;3:629-636.

50. Hatanaka M, Reis A, Sano ME, Susanna R Jr. Additive intraocular pressure reduction effect of fixed combination of maleate timolol $0.5 \%$ /dorzolamide $2 \%$ (Cosopt) on monotherapy with latanoprost (Xalatan) in patients with elevated intraocular pressure: a prospective, 4-week, open-label, randomized, controlled clinical trial. J Glaucoma. 2010;19(5):331-335.

51. Crichton AC, Harasymowycz P, Hutnik CM, et al. Effectiveness of dorzolamide-timolol (COSOPT) in patients who were treatment naive for open-angle glaucoma or ocular hypertension: the COSOPT first-line study. J Ocul Pharmacol Ther. 2010;26(5):503-511.

52. Cosopt [package insert-prescribing information]. Whitehouse Station, NJ: Merck \& Co., Inc.; 2009.

53. Beckers HJ, Schouten JS, Webers CA, van der Valk R, Hendrikse F. Side effects of commonly used glaucoma medications: comparison of tolerability, chance of discontinuation, and patient satisfaction. Graefes Arch Clin Exp Ophthalmol. 2008;246(10):1485-1490. 
54. Ammar DA, Kahook MY. The effects of combination glaucoma medications on ocular surface epithelial cells. Adv Ther. 2009;26(10): 970-975.

55. Santos VM, Castro RA, Lima CC, Moraes MB, Sugai TA. Skin eruption and thrombocytopaenia in a woman with glaucoma: a case report. West Indian Med J. 2010;59(1):102-105.
56. Yeh J, Kravitz D, Francis B. Rational use of the fixed combination of dorzolamide - timolol in the management of raised intraocular pressure and glaucoma. Clin Ophthalmol. 2008;2(2):389-399.

57. Rylander NR, Vold SD. Cost analysis of glaucoma medications. Am J Ophthalmol. 2008;145(1):106-113.

\section{Publish your work in this journal}

Clinical Ophthalmology is an international, peer-reviewed journal covering all subspecialties within ophthalmology. Key topics include: Optometry; Visual science; Pharmacology and drug therapy in eye diseases; Basic Sciences; Primary and Secondary eye care; Patient Safety and Quality of Care Improvements. This journal is indexed on

\section{Dovepress}

PubMed Central and CAS, and is the official journal of The Society of Clinical Ophthalmology (SCO). The manuscript management system is completely online and includes a very quick and fair peer-review system, which is all easy to use. Visit http://www.dovepress.com/ testimonials.php to read real quotes from published authors. 